\title{
Sedum Groundcover Variably Enhances Performance and Phenolic Concentrations of Perennial Culinary Herbs in an Urban Edible Green Roof
}

\section{Authors: Selena Ahmed, Sarabeth Buckley, Anne Elise Stratton, Feven Asefaha, Colleen Butler, Matthew Reynolds. and Colin Orians}

This is an Accepted Manuscript of an article published in Agroecology and Sustainable Food Systems on [date of publication], available online:

http://www.tandfonline.com/10.1080/21683565.2017.1279703.

Ahmed, Selena, Sarabeth Buckley, Anne Elise Stratton, Feven Asefaha, Colleen Butler, Matthew Reynolds, and Colin Orians. "Sedum Groundcover Variably Enhances Performance and Phenolic Concentrations of Perennial Culinary Herbs in an Urban Edible Green Roof." Agroecology and Sustainable Food Systems (March 2017): 487-504. DOI: 10.1080/21683565.2017.1279703. 


\title{
Sedum groundcover variably enhances performance and phenolic concentrations of perennial culinary herbs in an urban edible green roof*
}

\author{
Selena Ahmed ${ }^{a}$, Sarabeth Buckley ${ }^{b}$, Anne Elise Stratton', Feven Asefaha ${ }^{\mathrm{d}}$, \\ Colleen Butler, Matthew Reynolds ${ }^{f}$, and Colin Orians ${ }^{d}$
}

aSustainable Food and Bioenergy Systems Program, Department of Health and Human Development, Montana State University, Bozeman, Montana, USA; 'bepartment of Earth and Environment, Boston University, Boston, Massachusetts, USA; 'School of Natural Resources and Environment, University of Michigan, Ann Arbor, Michigan, USA; dDepartment of Biology, Tufts University, Medford,

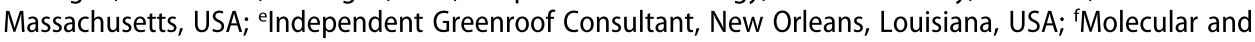
Cellular Biology Department, Harvard University, Cambridge, Massachusetts, USA

\begin{abstract}
Urban agriculture on green roofs has tremendous potential to enhance food security, economic opportunities, and community building in cities yet faces unique ecological challenges including limited soil moisture content for crops. We compared the effects of two green roof soil moisture management practices, sedum (Sedum album) groundcover versus watering, on performance and quality of three perennial culinary herbs: thyme, mint, and oregano. Individually and interactively, sedum groundcover and watering significantly impacted parameters of performance (biomass, vitality, and module coverage) and quality (total phenolic concentrations) of the three culinary herbs during early stages of establishment while having variable impacts during later developmental stages. Our results suggest that sedum groundcover can serve as a substitute for watering of hardy culinary herbs on green roofs on the basis of plant performance and quality. Findings can be applied to inform agroecological water management of herbs and other hardy specialty crops on green roofs toward enhancing their drought tolerance and advancing sustainable urban agriculture.
\end{abstract}

\section{KEYWORDS}

Crop quality; culinary herbs; green roofs; groundcover; perennials; sedum; specialty crops; urban agriculture; water management

\section{Introduction}

Urban agriculture is increasingly recognized as an important means to enhance food security, economic opportunities, and sense of community in cities in the movement toward sustainable food systems (Altieri et al. 1999; Drescher 2004; Food and Agriculture Organization of the United Nations 2005; Redwood 2009). However, labor, land, access to water sources, and other resource constraints, such

CONTACT Selena Ahmed selena.ahmed@montana.edu Sustainable Food and Bioenergy Systems Program, Department of Health and Human Development, Montana State University, Bozeman, MT 59717-2000, USA.

* $S A, C O$, and $C B$ designed the overall study objectives and research question. SA, CO, CB, FA, SB, and AES designed and implemented the experimental setup. FA led watering treatments. $S A, F A, S B, A E S$, and MR measured plant performance. FA and SB measured phenolic concentrations. SA, SB, and AES statistically analyzed the data. SA, SB, $A E S$, and $C O$ wrote the manuscript with feedback from all authors. 
as competition for space with various forms of urban development, place major resource limitations for the expansion of urban agriculture (Whittinghill and Rowe 2012). Edible green roofs, or rooftops vegetated with edible plants, offer the potential to tap into limited urban space for the cultivation of food. Green roofs further provide numerous environmental benefits including retention of storm water, lowering ambient air temperature, mitigating urban heat island effects, filtering air pollutants, providing insulation for buildings, and creating habitat for local fauna (Berndtsson, Bengtsson, and Jinno 2009; Kadas 2006; Kumar and Kaushik 2005; MacIvor and Lundholm 2011; Speak et al. 2012). On a socioeconomic and cultural basis, green roofs offer community building and aesthetic values and may support local livelihoods through the sale of harvests (Whittinghill and Rowe 2012; Whittinghill and Starry 2016).

In order for edible green roofs to be a viable option for urban agriculture, agroecosystem management practices need to be identified that best support sustainability by balancing resource use, environmental impacts of production, and added value for humans. Green roof environments place several unique ecological stressors on plants, including limited soil moisture content, extreme heat, high wind, and heightened solar radiation (Bousselot, Klett, and Koski 2011; Carter and Butler 2008). Unlike traditional agricultural production systems where plant roots have access to a relatively large reservoir of soil, the planning of an edible green roof must account for weight limits imposed by the structural support of the building on which it is housed. Buildings with high structural roof support may be able to accommodate intensive green roof systems with soil substrate of over $15 \mathrm{~cm}$, while many buildings not specifically designed for green roofs can only accommodate extensive green roof systems with shallow soil substrate of less than $15 \mathrm{~cm}$ (Kula 2005). Plants cultivated in extensive green roof systems, thus, have limited access to soil moisture content.

The ecological limitations faced by green roofs have the potential to be overcome through well-designed agroecosystem management plans that allow plants to endure the severe stress of a rooftop environment, such as summer water deficit, extreme heat, high wind, and heightened solar radiation (Carter and Butler 2008; Martin and Hinckley 2007; Retzlaff and Celik 2010). However, water for irrigation for managing water deficits is limited in many areas of the country and the world. Additionally, installing irrigation systems on green roofs can be cost prohibitive or have technical restraints. It is, thus, integral to identify sustainable strategies to reduce water demand of urban agriculture toward resilient food systems. This is particularly relevant in the context of climate change that is resulting in more severe droughts in many parts of the world (Trenberth et al. 2014).

Basic plant science and agroecology research can play a critical role to inform management solutions and good agricultural practices for managing water resources and the water deficit of agriculture toward fostering the expansion of green roofs and their feasibility for sustainable urban agriculture. Previous research has identified the practice of cultivating Sedum album (sedum; 
Crassulaceae), a low-growing succulent, as well as other sedum species as groundcover, and nurse plants in a green roof environment to serve as alternatives to intensive water management (Butler and Orians 2011; Heim and Lundholm 2014; Wolf and Lundholm 2008). Sedum is well adapted to the severe stress of a green roof environment due to its ability to survive long periods of water deficit and to grow rapidly when water is available (Carter and Butler 2008; Starry et al. 2014). In addition, sedum's form as groundcover and shallow root structure allows it to help the performance of neighboring plant species that may not otherwise survive in such high-stress environments by lowering soil temperatures (Butler and Orians 2011) and maintaining moisture content (Wolf and Lundholm 2008) without competing with deeper-rooted neighboring plants (Butler and Orians 2011). While intercropping sedum with more vulnerable plants has been identified as a good strategy in high-stress environments, there remains a need to identify best management practices for the use of sedum groundcover in designing urban green roofs in the context of food production.

The overall objective of this study is to compare the effects of two green roof practices for managing soil moisture content, sedum groundcover, and water management, on the performance and quality of culinary herbs during various stages of plant development. Culinary herbs are relatively small in stature and, thus, make ideal candidates for cultivating on rooftop gardens. We examine three perennial, drought-tolerant culinary herbs in the mint (Lamiaceae) family that are native to an arid Mediterranean environment: silver thyme (Thymus argenteus), Moroccan mint (Mentha spicata), and Italian oregano (Organum majoricum). Previous work has shown that sub-Mediterranean plants are particularly well suited to extensive green roof environments because of their adaptation to drought and harsh weather conditions (Van Mechelen, Dutoit, and Hermy 2014). Thyme, mint, and oregano are widely cultivated for their culinary value as seasonings as well as for their roles in health and disease prevention.

In addition to performance, it is important to measure crop quality when examining the impact of environmental factors and management practices on agriculture (Ahmed et al. 2014, Ahmed and Stepp 2016). The quality of specialty crops including herbs, fruits, and vegetables is multidimensional and encompasses flavor, appearance, shelf-stability, and health-promoting properties (Tomás-Barberán and Espín 2001). There is increasing recognition that the polyphenolic class of phytochemicals contributes to the multiple dimensions of crop quality (Tomás-Barberán and Espín 2001). Phenolics serve as defense compounds in plants and are well known to vary in concentration depending on environmental conditions and agroecological practices (Ahmed et al. 2013, Ahmed and Stepp 2016; Coley and Barone 1996).

We hypothesized that sedum mimics the effect of water management on parameters of plant performance (biomass, vitality, and module coverage) and quality (total phenolic concentrations) and serves the greatest nurse 
plant function during early stages of development, when plants are most vulnerable to stress. The key translational goal of this research is to inform good agricultural practices and resource utilization for the development and maintenance of edible green roofs to facilitate the expansion of sustainable urban agriculture. While this research focuses on culinary herbs, findings have the potential to inform other hardy specialty crops and perennials.

\section{Methods}

Research was carried out during a 14-week summer period in the northeastern United States, using three consecutive experimental harvests to understand variation of culinary herb responses to sedum intercropping versus water management during multiple ontological stages at a time of limited water availability. Plant performance was determined on the basis of module coverage, vitality, and dried plant biomass. Plant quality of the herbs was measured on the basis of total phenolic concentration as phenolic compounds are recognized as determinants of quality of specialty crops (Tomás-Barberán and Espín 2001). Although the unique flavor and therapeutic profiles of these culinary herbs are attributed to three classes of secondary metabolites that determine their functional quality, polyphenols, terpenes, and essential oils (Stagos et al. 2012), we focused on phenolics because this class of phytochemicals is most recognized to influence specialty crop quality (Tomás-Barberán and Espín 2001) and overall human health attributes including antioxidant and anti-inflammatory properties for human consumers (Kogiannou et al. 2013).

\section{Study species}

Sedum album was purchased from Emory Knoll Farms (Street, MD, USA) and used as a groundcover treatment species intercropped with our focal culinary herbs. Seedling plugs of USDA-certified organic silver thyme (Thymus argenteus), Moroccan mint (Mentha spicata), and Italian oregano (Organum majoricum) were purchased from Mountain Valley Growers (Squaw Valley, CA, USA). Silver thyme grows well in USDA Hardiness zones 4-11. Seedlings were two weeks old when they arrived and were transplanted into the green roof system.

\section{Study site and green roof design}

Research was conducted in a modular extensive green roof system established at Tufts University's Tisch Library (Medford, MA, USA) in the northeastern United States. The system consists of black plastic modules that are $38 \mathrm{~cm} \times$ $38 \mathrm{~cm} \times 13 \mathrm{~cm}$ in dimension. Each module was filled with a 13-cm-deep layer of blended growing substrate composed of 55:30:15 expanded shale 
aggregate, sand, and leaf compost purchased from Read Custom Soils (Canton, MA, USA). Field capacity of the substrate was previously established as $0.35 \mathrm{~cm}^{3}$ water $/ 1 \mathrm{~cm}^{3}$ substrate (Butler and Orians 2011). Pellets of controlled-release fertilizer (Osmocote Plus 15-9-12 from Scotts Miracle-Gro in Marysville, OH, USA) were mixed into the top $2 \mathrm{~cm}$ of the substrate at a concentration of $3.6 \mathrm{~g}$ fertilizer per liter media. Experimental modules were arranged in rows of two surrounded with a module of Sedum album on both ends of the row in order to buffer against edge effects.

\section{Experimental design and treatments}

Modules were used as the unit of replication. Each module contained a single focal herb species for a total of 28 module replicates per species and 7 replicates per species treatment with Sedum album and water input. Focal herbs were grown in the modules from seedling plugs at a density of four plants per module equidistant in space. Plant locations within the module were labeled as position \#1-4. Modules of focal herb species were randomly arranged within the experimental rows to eliminate a location effect. Half of the modules equally representing each focal species were demarcated as "high water" treatments, and the other half of the modules were demarcated as "low water" treatments. Within each water treatment group, half of the modules were randomly selected to have sedum groundcover, while the other half of the modules did not receive a groundcover treatment.

The high water regime involved watering modules every other day to saturation unless it rained enough to bring the substrate to saturation. The low water regime involved watering modules only in the event that there was no rain for two weeks, in which case they would be watered once weekly to saturation until the next rainfall. Water treatments were designed based on prior green roof experiments (Butler and Orians 2011) as well as green roof maintenance guides. In general, plants on green roofs are selected for their drought tolerance, and these hardy plants may need to be watered if there is less than half an inch of rainfall during a 2week period or sooner for prolonged temperatures above $85^{\circ} \mathrm{F}$ depending on the specific plant thresholds.

Water treatments started one week after the herbs were transplanted. Prior to treatment, herbs were watered to saturation every other day for the first week after transplanting. Due to weather patterns during experimentation, the low-water modules were never watered. Sedum album was transplanted from the existing green roof population to initially cover $50 \%$ of the groundcover treatment modules (sedum took root within 10 days of transplantation).

Experiments were conducted between June 15 and September 15, representing three consecutive harvest periods to capture various ontological stages of plant development of the three perennial culinary herbs: 1) harvest 1 was carried out on July 15, when the culinary herbs were 6 weeks of age (young developmental stage); 2) harvest 2 was carried out on August 15, when the culinary herbs were 10 weeks 
of age (intermediate developmental stage); and 3) harvest 3 was carried out on September 15, when the culinary herbs were 14 weeks of age and were flowering (mature developmental stage). Mint, thyme, and oregano can be continuously harvested and are considered to have optimal flavor right before flowering. Our experiments were, thus, designed for a 3-month period to encapsulate the optimal harvest period for these culinary herbs.

Rainfall during each harvest period varied as follows: 1) 2.39 inches during month 1 prior to harvest 1,2) 6.63 inches during month 2 prior to harvest 2 , and 3 ) 1.84 inches during month 3 prior to harvest 3 . The mean temperature during each harvest period varied as follows: 1) $74.2^{\circ} \mathrm{F}$ during month 1 prior to harvest 1,2 ) $75.48^{\circ} \mathrm{F}$ during month 2 prior to harvest 2 , and 3) $71.23^{\circ} \mathrm{F}$ inches during month 3 prior to harvest 3 . The average maximum temperature during each harvest period varied as follows: 1) $82.4^{\circ} \mathrm{F}$ during month 1 prior to harvest 1,2$) 82.65^{\circ} \mathrm{F}$ during month 2 prior to harvest 2 , and 3) $78.84^{\circ} \mathrm{F}$ inches during month 3 prior to harvest 3. In total, there were 12 days during month 1 where the temperature was above $85^{\circ} \mathrm{F}, 10$ days during month 2 and four days during month 3 .

\section{Plant performance}

We measured plant biomass, module coverage, and vitality at each experimental harvest. Module coverage of focal species herbs was visually quantified and estimated to the nearest $10 \%$. Vitality was measured as a percentage of viability (scored on a matrix of appearance of health) and death of focal herb species.

\section{Phenolic concentration}

We measured total phenolic concentration (TPC) at three separate harvests using the Folin-Ciocalteau reagent method as previously described (Unachukwu et al. 2010). At the end of each of the three experimental periods, one plant from the same position within each module was harvested at the base using sharp shearing scissors. Harvested plants were transferred to a lyophilizer (VirTis, SP Scientific, Warminster, PA, USA) for a drying period of 48 hours. Dry weights were recorded upon removing the plants from the lyophilizer as a measure of dried plant biomass. Plants were then stored at $4^{\circ} \mathrm{C}$ until sample extraction.

For each sample, $20 \mathrm{mg}$ of finely pulverized, dried leaf material was extracted in $1.5 \mathrm{~mL} \mathrm{80 \%} \mathrm{aqueous} \mathrm{HPLC-grade} \mathrm{methanol} \mathrm{(Fisher} \mathrm{Scientific,} \mathrm{Fair} \mathrm{Lawn,} \mathrm{NJ,}$ USA). The resulting mixture was vortexed for $30 \mathrm{sec}$ (Genie 2, Fisher Scientific, Fair Lawn, NJ, USA) and sonicated for $30 \mathrm{~min}$ at $20^{\circ} \mathrm{C}$ (Quantrex 280, L\&R Ultrasonics, Kearney, NJ, USA). The samples were centrifuged following sonication for $15 \mathrm{~min}$ at 15,000 rpm (Marathin Micro A, Fisher Scientific), and the supernatant was transferred to new microcentrifuge tubes. 
Samples were analyzed for TPC in triplicates. Absorbance values were measured at $765 \mathrm{~nm}$ using a Benchmark Plus Microplate Spectrometer (Bio-Rad, Hercules, CA, USA), and results expressed as gallic acid equivalents (GAE) in $\mathrm{mg} \mathrm{g}^{-1}$ dry plant material. The concentration of polyphenols in the culinary herb samples was derived from a standard curve of gallic acid concentration versus absorbance between 31.25 and $500 \mathrm{~g} \mathrm{~mL}^{-1}$.

\section{Statistical analysis}

A mixed effects fit model using a standard least squares means function and analysis of variance was performed using JMP 10.0 (SAS Institute Inc., Middleton, MA, USA) to determine how plant performance and functional quality of the combined culinary herbs varies among the sedum groundcover (sedum and no sedum) and water management (low water and high water) treatments for each stage of development (young, intermediate, and mature). This model allows for combining the data for the three culinary herbs. Data were analyzed for the overall effect of sedum groundcover, water treatment, and their interactive effects. In addition, a multiple comparison using the least squares means Tukey's HSD method was applied to examine differences between the three stages of development for each species. A linear regression was used to determine the relationship between plant biomass and functional quality.

\section{Results}

\section{Plant performance}

During the early stage of plant development (harvest 1), the combined individual and interactive effects of the sedum groundcover and water treatments significantly impacted all of the performance parameters of the three culinary herbs, including module coverage $(p=0.005)$, dried plant biomass $(p=0.012)$, and vitality $(p=0.009)$. When the culinary herbs were establishing (young stage of development), the sedum treatment had a positive effect on module ground coverage ( $p=0.051$; Figure 1a) but did not have a significant impact on dried plant biomass ( $p=0.848$; Figure 2a) or vitality ( $p=0.075$; Figure 3a). During this stage of development, the water treatment significantly increased module ground coverage ( $p=0.003$; Figure 1a), dried plant biomass $(p=0.001$; Figure $2 \mathrm{a})$, and vitality ( $p=0.033$; Figure $3 \mathrm{a})$. The interactive effect of the sedum and water treatments significantly impacted plant vitality $(p=0.033$; Figure 3a) but did not significantly impact module coverage ( $p=0.439$; Figure 1a) or plant biomass $(p=0.671$; Figure 2a.).

After 10 weeks (intermediate stage; harvest 2), the individual and interactive effects of the sedum groundcover and water treatments significantly impacted module coverage $(p=0.005)$, biomass $(p=0.004)$, and vitality 

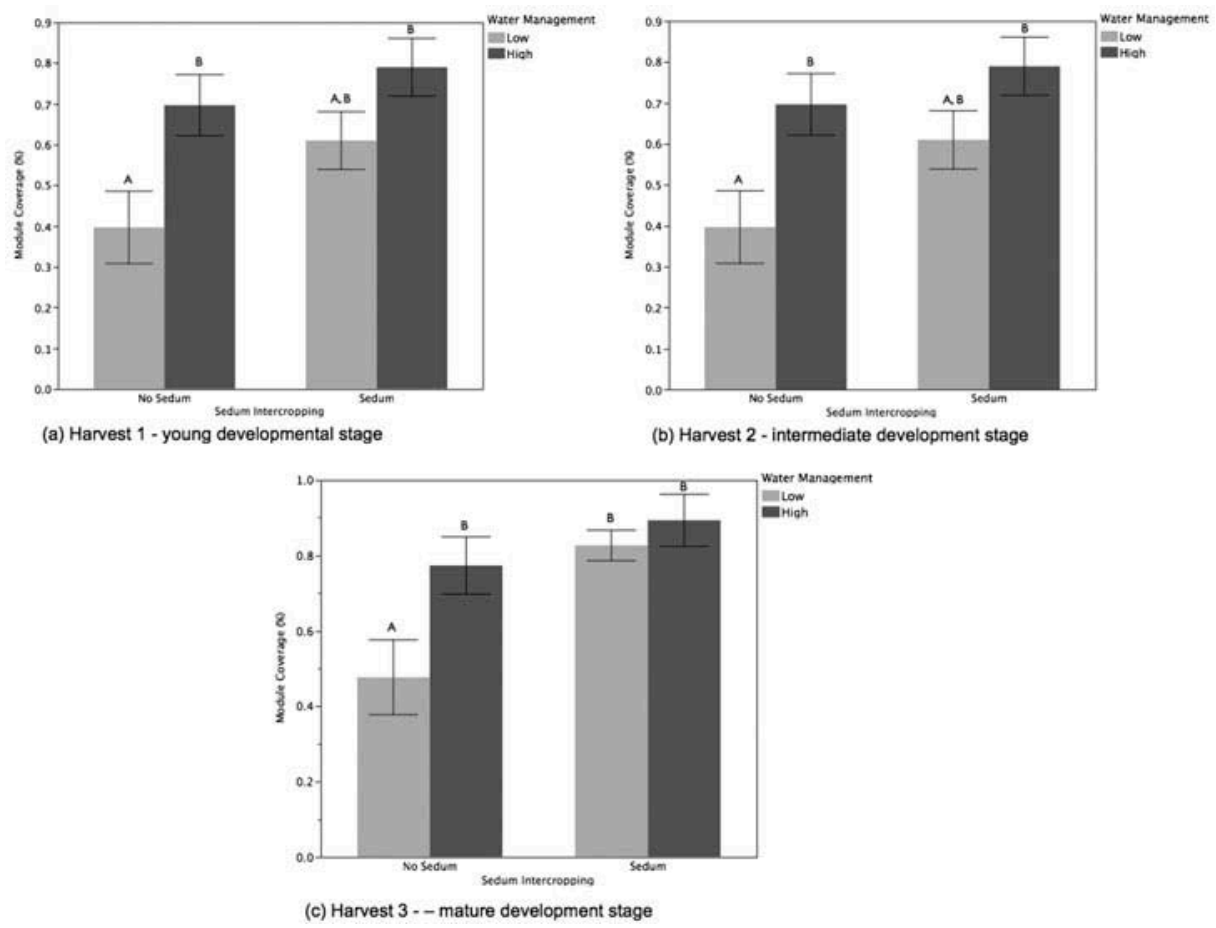

Figure 1. Effects of sedum groundcover and water management treatments on the performance measure of module coverage (\%) of culinary herbs in an edible green roof during three stages of plant development: a) young developmental stage (harvest 1), b) intermediate development stage (harvest 2), and c) mature developmental stage (harvest 3).

$(p=0.003)$ of the three culinary herbs. Sedum groundcover increased module coverage ( $p=0.003$; Figure $1 b)$, plant biomass $(p=0.004868$; Figure $2 \mathrm{~b}$ ), and vitality ( $p=0.004$; Figure $3 \mathrm{~b}$ ) of the culinary herbs during the intermediate stages of plant development. The water treatment significantly increased module coverage $(p=0.003$; Figure $1 \mathrm{~b})$, dried plant biomass $(p<0.001$; Figure $2 b)$, and vitality $(p=0.004$; Figure $3 b)$ of the culinary herbs. The interactive effect of the sedum and water treatments did not significantly impact module coverage $(p=0.439$; Figure $1 b)$, dried plant biomass $(p=0.447$; Figure $2 b)$, and plant vitality $(p=0.205$; Figure $3 b)$.

After 14 weeks (mature stage; harvest 3), the combined individual and interactive effects of the sedum and water treatments significantly impacted module coverage $(p=0.001)$ and vitality $(p=0.001)$ of the three culinary herbs but did not significantly impact dried plant biomass $(p=0.097)$. The sedum treatment significantly increased module coverage $(p=0.008$; Figure $1 c)$ and vitality $(p=0.002$; Figure $3 c$ ) of the culinary herbs during this mature stage of plant development but did not have a significant impact on dried plant biomass $(p=0.177$; Figure $2 c)$. The water treatment 


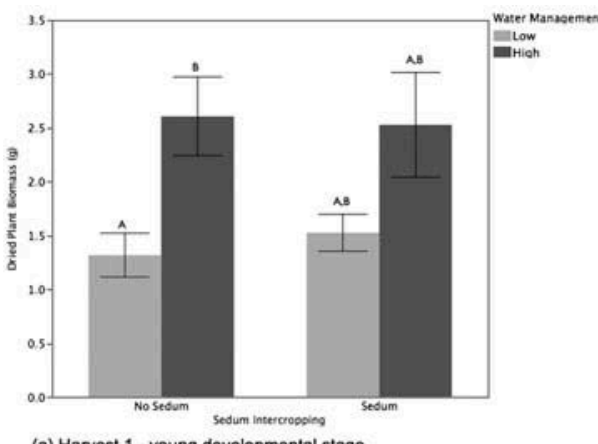

(a) Harvest 1 - young developmental stage

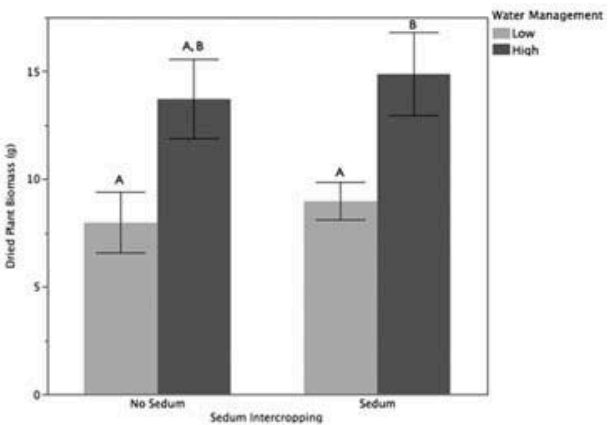

(b) Harvest 2 - intermediate development stage

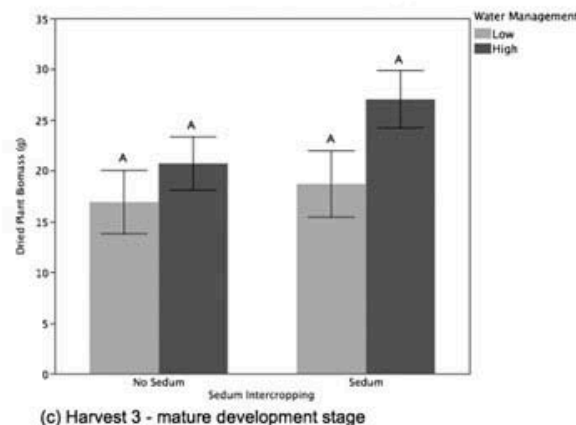

(c) Harvest 3 - mature development stage

Figure 2. Effects of sedum groundcover and water management treatments on the performance measure of dried plant biomass $(\mathrm{g})$ of culinary herbs in an edible green roof during three stages of plant development: a) young developmental stage (harvest 1), b) intermediate development stage (harvest 2), and c) mature developmental stage (harvest 3).

significantly increased module coverage ( $p=0.017$; Figure 1c), dried plant biomass $(p=0.045$; Figure $2 c)$, and vitality $(p=0.003$; Figure $3 c)$ of the culinary herbs during this mature stage of plant development. The interactive effect of the sedum and water treatments did not significantly impact module coverage ( $p=0.439$; Figure $1 c)$, dried plant biomass $(p=0.126$; Figure $2 c)$, and plant vitality $(p=0.158$; Figure $3 c)$.

Significant variation was found between the individual culinary herb species for performance parameters. During the early stage of plant development (harvest 1 ), species type accounted for $32.14 \%$ of the variance in dried plant biomass. Mint $(p=0.0001)$ and oregano $(p<0.001)$ were significantly higher biomass than thyme (Figure 5a).

\section{Phenolic concentration}

During the early stage of plant development, combined individual and interactive effects of the sedum groundcover and water treatments significantly impacted plant total phenolic concentration $(p=0.0421)$. Individually, the sedum treatment significantly increased phenolics $(p=0.009$; Figure $4 \mathrm{a})$ of the culinary herbs, while the water treatment did not $(p=0.863$; 


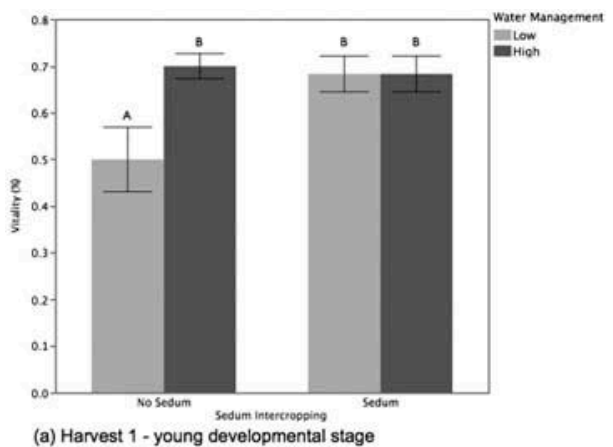

(a) Harvest 1 - young developmental stage

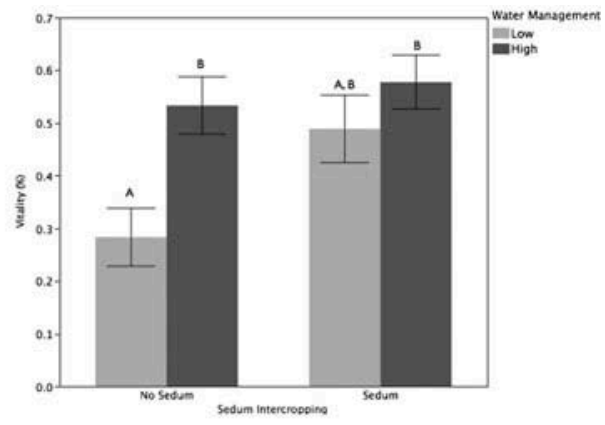

(b) Harvest 2 - intermediate development stage

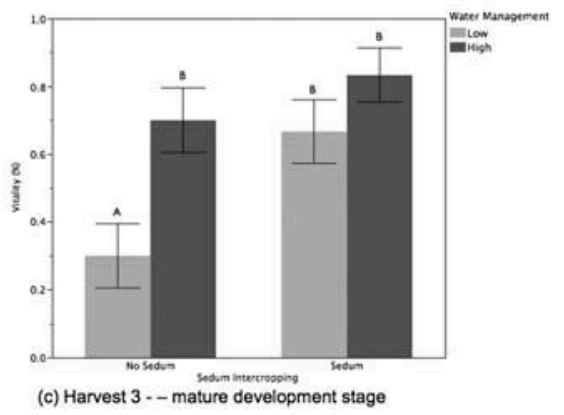

Figure 3. Effects of sedum groundcover and water management treatments on the performance measure of vitality (\%) of culinary herbs in an edible green roof during three stages of plant development: a) young developmental stage (harvest 1), b) intermediate development stage (harvest 2), and c) mature developmental stage (harvest 3).

Figure $4 \mathrm{a})$. The interactive effects of the sedum and water treatments also did not significantly impact phenolic concentrations $(p=0.326)$.

At harvest 2, the combined individual and interactive effects of the sedum groundcover and water treatments did not significantly impact phenolic levels $(p=0.838)$. Neither the sedum groundcover treatment $(p=0.626$; Figure $4 \mathrm{~b}$ ), the water management treatment ( $p=0.449$; Figure $4 \mathrm{~b})$, nor their interactive effects $(p=0.893)$ had a significant impact. Likewise, during harvest 3 (mature stage of development), the combined individual and interactive effects of the sedum groundcover and water treatments did not significantly impact phenolic concentrations $(p=0.243)$. Neither the sedum groundcover treatment $(p=0.122$; Figure $4 c)$ nor the water management treatment $(p=0.122$; Figure $4 c)$ and their interactive effects $(p=0.305)$ had a significant impact.

There was significant variation in total phenolics among these culinary herbs $(p=0.0009)$ with mint $(p=0.0019)$ and oregano $(p=0.0022)$ having significantly higher levels than thyme (Figure $5 b$ ). During the early stages of plant development (harvest 1), species type accounted for $23.75 \%$ of the variance in functional quality. 


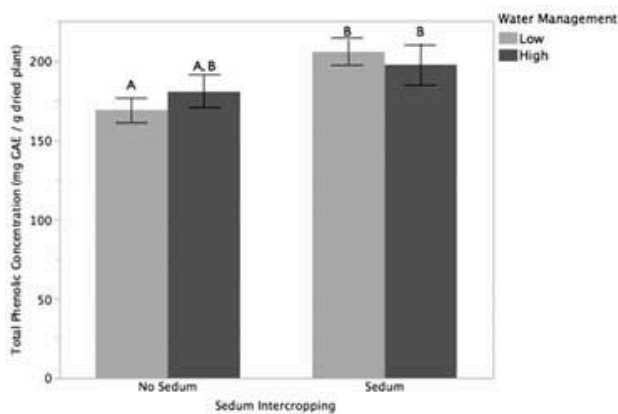

(a) Harvest 1 - young developmental stage

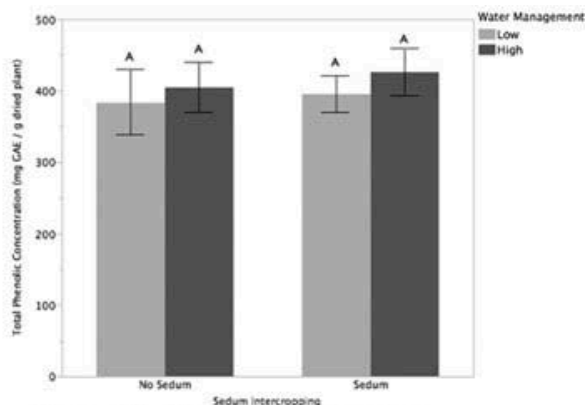

(b) Harvest 2 - intermediate development stage

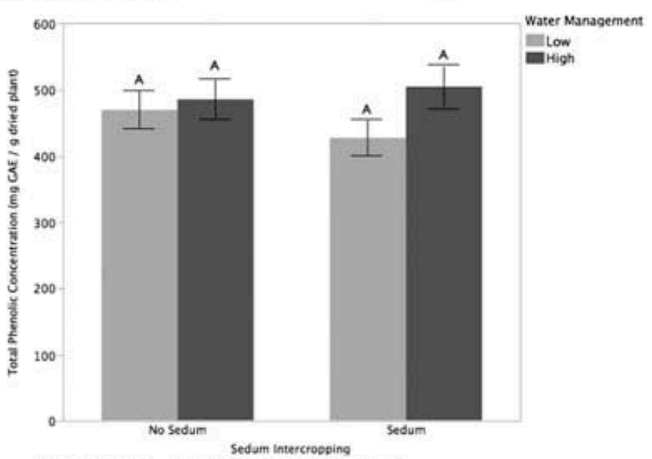

(c) Harvest 3 - mature development stage

Figure 4. Effects of sedum groundcover and water management treatments on the plant quality measure (total phenolic concentration, TPC) of edible green roof plants during three stages of plant development: a) young developmental stage (harvest 1), b) intermediate development stage (harvest 2), and c) mature developmental stage (harvest 3).
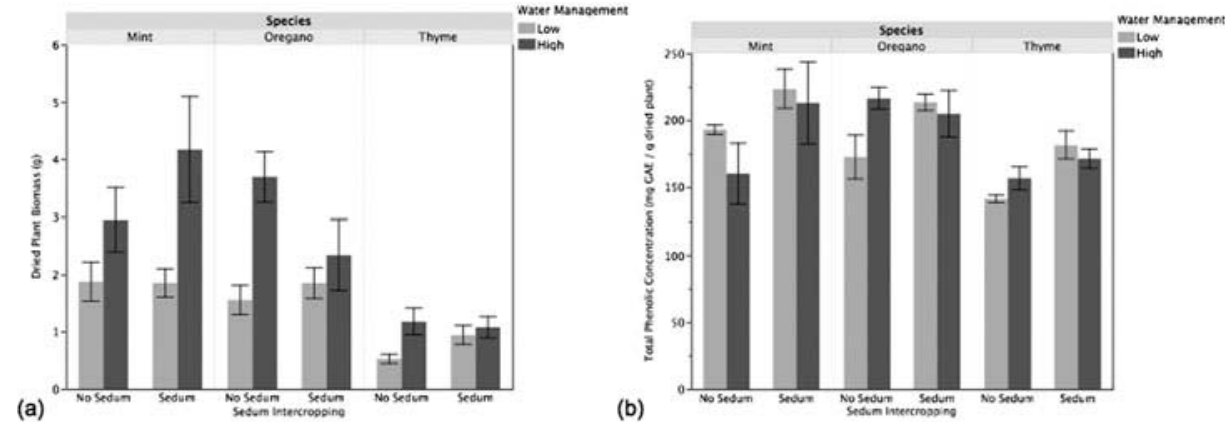

Figure 5. Significant variation was found between the individual culinary herb species for performance and functional quality parameters in response to the sedum groundcover and water management treatments. For harvest 1 , species type significantly impacted the plant performance metric of dried plant biomass (a) and the functional quality parameter of total phenolic concentration (TPC; b).

\section{Relationship of plant performance to phenolic quality}

An increase in the plant performance trait of dried plant biomass was associated with a trend of increased phenolic concentrations during all stages of plant development. However, regression analysis found that the data did 
not have a close fit to the linear model line (Figure 6.; $R^{2}=0.12, p=0.006$ for harvest $1 ; R^{2}=0.12, p=0.008$ for harvest 2 and; $R^{2}=0.14, p=0.005$ for harvest 3).

\section{Discussion}

Our findings indicate that the effects of sedum groundcover and water management on neighboring culinary herbs are similar and highly dependent on the stage of plant development. While watering has a large effect on culinary herb growth, sedum groundcover can also enhance the performance of neighboring plants when water is limiting. In addition, we found that our measure of quality, total phenolic concentration, was impacted by both the sedum and water treatments. Overall, our results suggest that sedum groundcover can serve as a substitute for soil moisture management on urban green roofs for hardy culinary herbs and potentially for other hardy specialty crops and perennials. Our findings are particularly relevant for sustainable urban agriculture as intensive water management may not be an option due to limited water available for irrigation as well as cost and technical restraints in installing irrigation systems on green roofs. These findings are further relevant in the context of climate change with more severe droughts in many parts of the world (Trenberth et al. 2014).

This study contributes to the body of research providing evidence of the role of sedum groundcover as a nurse plant by enhancing the performance of neighboring plants on green roofs and serving as an alternative to intensive water management (Butler and Orians 2011; Heim and Lundholm 2014;

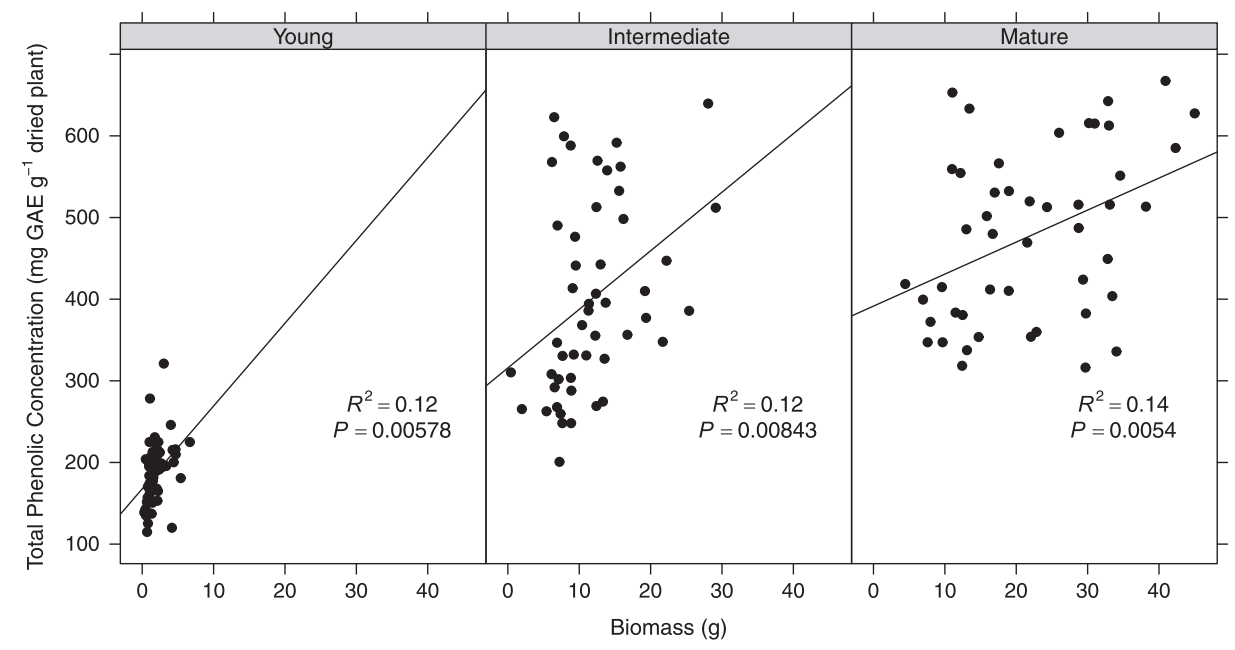

Figure 6. Relationship between plant quality (total phenolic concentration, TPC) and dried plant biomass $(\mathrm{g})$ of culinary herbs in an edible green roof. TPC increased significantly with biomass during three stages of plant development: a) young developmental stage (harvest $1 ; R^{2}=0.12$, $p=0.00578), \mathrm{b}$ ) intermediate development stage (harvest $2 ; R^{2}=0.12, p=0.00843$ ), and $c$ ) mature developmental stage (harvest $3 ; R^{2}=0.14, p=0.0054$ ). 
Wolf and Lundholm 2008). In addition to plant performance, this study provides evidence that sedum groundcover impacts the performance of neighboring plants on the basis of functional quality as measured by total phenolic concentrations. Our findings also show that sedum groundcover variably impacts the performance and quality of neighboring plants depending on their ontological stage. Specifically, we found that sedum groundcover significantly impacts all of the performance parameters as well as quality of the three culinary herbs during the early stages of development, while having variable impacts during the intermediate and mature stages of development. During the intermediate stages of plant development, the individual and combined effects of the sedum and water treatments significantly impacted all of the plant performance characteristics of the culinary herbs and did not significantly impact quality. During the mature stages of plant development, the individual and combined effects of the sedum and water treatments significantly impacted two of the three plant performance characteristics (module coverage and vitality) of culinary herbs and did not significantly impact the performance parameter of dried plant biomass. In addition, the individual and combined effects of the sedum and water treatments did not significantly impact the functional quality parameter of total phenolic concentration during the mature stages of plant development. On the basis of these findings, we can conclude that plant biomass and functional quality parameters are the most sensitive to plant ontogeny of the traits measured for the three culinary herbs examined, and the early stages of plant establishment are the most sensitive to management regime.

The soil moisture management practices examined in this study notably impacted total phenolic concentrations with variation between 3 and 40\% depending on the specific treatment, culinary herb, and developmental stage at time of harvest. Total phenolic concentrations of culinary herbs were up to $40 \%$ higher in the presence of sedum. These differences in total phenolic concentrations are relevant from a quality perspective in influencing the flavor, appearance, shelf-stability, and human-health-promoting properties of crops (Tomás-Barberán and Espín 2001).

Several of our findings regarding the variation in levels of phenolic concentrations with management practices are contrary to theories in the literature or may seem counterintuitive. The trend that we observed of an increase in the plant performance trait of dried plant biomass to be associated with increased phenolic concentrations is not in line with the dilution effect theory of chemical ecology that states that when growth conditions are favorable, less secondary chemicals will be produced as a resource trade off (Nurmi et al. 1996; Riipi et al. 2002). However, several other studies have found similar trends as in our study regarding the ability of plants to support both growth and defense (Briggs and Schultz 1990; Riipi et al. 2002; Sene, Dore, and Gallet 2001). Additionally, our results are not in line with the optimal defense theory of chemical ecology 
(McKey 1974; Rhoades 1979) that states that phenolic content will be higher in young leaves that are in greatest need of protection. Our findings of the relatively low levels of phenolic concentration for the highest stress treatment (no sedum and low water) may further seem counterintuitive given that phenolic concentration is often higher in more stressed plants according to chemical ecology theories (Bryant, Chapin, and Klien 1983; ; Briggs and Schultz 1990; Nichols-Orians 1991; Zietz et al. 2010). We suggest two possible explanations for this finding. As Briggs and Schultz (1990) found in Lotus corniculatus, larger plants may have the resources to support both growth and defense. Alternatively, if stress levels exceed thresholds where plants lose their ability to perform normal functions, plant senescence ensues and concentrations drop (Ayres 1993; Chaves et al. 2002; Porter and Semenov 2005). Perhaps the culinary herbs in our study did not have enough metabolic energy under the most stressful conditions to grow and to produce phenolics. Our findings highlight that the production of phenolics is a complicated response to multiple stimuli, which is consistent with the multitude of functions they serve. Future studies on the effects of multiple environmental and management factors on phenolic and other secondary metabolites are needed to elucidate an integrated theory driving plant phenolic concentrations that influence crop quality.

While this study focused on hardy perennial culinary herbs, results have the potential to inform the management of other specialty crops and perennials including fruits and vegetables. Future research is needed to examine the effect of sedum groundcover on other specialty crops in a green roof environment to support urban agriculture. In addition, future research is needed to examine the effects of sedum groundcover on additional parameters of crop quality including other classes of secondary metabolites including terpenoids as well as sensory aspects.

\section{Conclusions}

This is the first study to our knowledge that assesses the role of sedum groundcover in mediating both the performance and the phenolic concentrations of culinary herbs. While edible green roofs offer the potential to tap into limited urban space for the cultivation of food, there is a need to identify agroecosystem management practices that best support agricultural sustainability by balancing resource use, environmental impacts of production, and added value for humans. This study is in line with previous studies of the role sedum groundcover as an alternative to intensive water management on urban green roofs. Sedum groundcover shows promise in mitigating the effects of high-stress green roof environments by supporting neighboring plant performance, thereby serving a nurse plant function. In addition to measuring performance characteristics, we further highlight the need to focus on evaluating the impact of agroecological management on quality of edible plants. Findings suggest that sedum treatments variably impact 
phenolic quality depending on stages of development, with a significant effect on plants during their early ontogenical stages. Future research is needed to examine the effects of sedum ground cover on a range of other specialty crops that can be grown on a green roof, including hardy and perennial fruits and vegetables. Results of this study have potential applications in developing green roof management plans and good agricultural practices for urban agriculture through an evidencebased approach. Water and associated labor resources can be best used in conjunction with sedum groundcover during the early stages of plant development when plants are establishing themselves. Adoption of such management practices would allow water resources to be conserved during later stages of plant development. The creation and maintenance of green roofs composed of high-quality culinary herbs, and other specialty crop species could become more feasible with the option to limit watering in edible green roofs with sedum ground cover. Future specialty crop studies are called for to further inform optimal green roof management practices and resource utilization as society moves forward with sustainable urban agriculture initiatives. Expanding urban agriculture could enhance food security and other environmental services through increased availability of spaces for local food production in city environments.

\section{Acknowledgments}

We would like to thank: Coco Gomez for providing feedback on the experimental setup of the study; George Ellmore for supporting with water treatments; Tufts University Library and facilities for their support in hosting the green roof experimental setup.

\section{Funding}

This study was funded by the National Science Foundation Research Experiences for Undergraduates Program (NSF DBI 1005082), the Tufts Institute for the Environment at Tufts University, and the TEACRS Program at Tufts University (NIH National Institute of General Medical Sciences IRACDA-K12GM074869).

\section{References}

Ahmed, S., C. M. Peters, L. Chunlin, R. Meyer, U. Unachukwu, A. Litt, E. Kennelly, and J. R. Stepp. 2013. Biodiversity and phytochemical quality in indigenous and state-supported tea management systems of Yunnan, China. Conservation Letters 5:28-36. doi:10.1111/j.1755263X.2012.00269.x.

Ahmed, S., and J. R. Stepp. 2016. Beyond yields: Climate effects on specialty crop quality and agroecological management. Elementa: Science of the Anthropocene (Forum on New Pathways to Sustainability in Agroecological Systems) 4:000092.

Ahmed, S., J. R. Stepp, C. Orians, T. Griffin, C. Matyas, A. Robbat, et al. 2014. Effects of extreme climate events on tea (Camellia sinensis) functional quality validate indigenous farmer knowledge and sensory preferences in tropical China. PLOS ONE 9:e109126. doi:10.1371/journal.pone.0109126. 
Altieri, M., N. Companioni, K. Cañizares, C. Murphy, P. Rosset, M. Bourque, and C. Nicholls. 1999. The greening of the "barrios": Urban agriculture for food security in Cuba. Agriculture and Human Values 16:131-40. doi:10.1023/A:1007545304561.

Ayres, M. P. 1993. Plant defense, herbivory, and climate change. In Biotic interactions and global change, eds. P. M. Kareiva, J. G. Kingsolver, and R. B. Huey, 75-94. Sunderland, MA: Sinauer Associates.

Berndtsson, J. C., L. Bengtsson, and K. Jinno. 2009. Runoff water quality from intensive and extensive vegetated roofs. Ecological Engineering 35:369.

Bousselot, J. M., J. E. Klett, and R. D. Koski. 2011. Moisture content of extensive green roof substrate and growth response of 15 temperate plant species during dry down. Hort Science 46(3):518-22.

Briggs, M. A., and J. C. Schultz. 1990. Chemical defense production in Lotus Corniculatus L. II. Trade-offs among growth, reproduction and defense. Oecologia 83:32-37. doi:10.1007/ BF00324630.

Bryant, P., F. S. Chapin, III, and D. R. Klien. 1983. Carbon/nutrient balance of boreal plants in relation to vertebrate herbivory. Oikos 40:357-68. doi:10.2307/3544308.

Butler, C., and C. M. Orians. 2011. Sedum cools soil and can improve neighboring plant performance during water deficit on a green roof. Ecological Engineering 37:1796-803. doi:10.1016/j.ecoleng.2011.06.025.

Carter, T., and C. Butler. 2008. Ecological impacts of replacing traditional roofs with green roofs in two urban areas. Cities and the Environment 1:1-17. Article 9. doi:10.15365/cate.

Chaves, M. M., J. S. Pereira, J. Maroco, M. L. Rodrigues, C. P. Ricardo, M. L. Osoâ Rio, I. Carvalho, T. Faria, and C. P. Inhe Iro. 2002. How plants cope with water stress in the field: Photosynthesis and growth. Annals of Botany 89:907-16. doi:10.1093/aob/mcf105.

Coley, P. D., and J. A. Barone. 1996. Herbivory and plant defenses in tropical forests. Annual Review of Ecology and Systematics 27:305-35. doi:10.1146/annurev.ecolsys.27.1.305.

Drescher, A. W. 2004. Food for the cities: Urban agriculture in developing countries. In Proceedings of the international conference on urban horticulture, acta horticulae number 63, ed. R. Junge-Berberovic, J. B. Bächtiger, and W. J. Simpson, 643 227-31. International Conference on Urban Horticulture.

Food and Agriculture Organization of the United Nations. 2005. Farming in urban areas can boost food security. FAONewsroom. http://www.fao.org/newsroom/en/news/2005/102877/ index.html (accessed January 31, 2016)

Heim, A., and J. Lundholm. 2014. Species interactions in green roof vegetation suggest complementary planting mixtures. Landscape and Urban Planning 130:125-33. doi:10.1016/j.landurbplan.2014.07.007.

Kadas, G. 2006. Rare invertebrates colonizing green roofs in London. Urban Habitats 4:66-73.

Kogiannou, D. A., N. Kalogeropoulos, P. Kefalas, M. G. Polissiou, and A. C. Kaliora. 2013. Herbal infusions; their phenolic profile, antioxidant and anti-inflammatory effects in HT29 and PC3 cells. Food Chemistry and Toxicology 61:152-59. doi:10.1016/j.fct.2013.05.027.

Kula, R. 2005. Green roofs and the LEED green building rating system. Proceedings of the 3rd North American Green Roof Conference: Greening Rooftops for Sustainable Communities, Washington, DC.

Kumar, R., and S. C. Kaushik. 2005. Performance evaluation of green roof and shading for thermal protection of buildings. Building and Environment 40:1505-11. doi:10.1016/j. buildenv.2004.11.015.

MacIvor, J. S., and J. Lundholm. 2011. Insect species composition and diversity on intensive green roofs and adjacent level-ground habitats. Urban Ecosystems 14:225-41. doi:10.1007/ s11252-010-0149-0. 
Martin, M. A., and T. M. Hinckley. 2007. Native plant performance on a Seattle green roof. Paper presented at the annual Greening Rooftops for Sustainable Communities Conference, Minneapolis, MN.

McKey, D. 1974. Adaptive patterns in alkaloid physiology. American Naturalist 108:305-20.

Nichols-Orians, C. M. 1991. Environmentally induced differences in plant traits: Consequences for susceptibility to a leaf-cutter ant. Ecology 72:1609-23. doi:10.2307/ 1940961.

Nurmi, K., B. Ossipov, E. Haukioja, and K. Pihlaja. 1996. Variation of total phenolic content and individual low-molecular-weight phenolics in foliage of mountain birch trees (Betula pubescens ssp. tortuosa). Journal of Chemical Ecology 22:2023-40. doi:10.1007/BF02040093.

Porter, J. R., and M. A. Semenov. 2005. Crop responses to climatic variation. Philosophical Transactions of the Royal Society B 360:2021-35. doi:10.1098/rstb.2005.1752.

Redwood, M., ed. 2009. Agriculture in urban planning: Generating livelihoods and food security. Sterling, VA: Earthscan.

Retzlaff, B., and S. Celik. 2010. Into the wind: Wind tunnel testing of green roof systems. Paper Presented at CitiesAlive Conference, Vancouver, BC, Canada.

Riipi, M., V. Ossipov, K. Lempa, E. Haukioja, J. Koricheva, S. Ossipova, and K. Pihlaja. 2002. Seasonal changes in birch leaf chemistry: Are there trade-offs between leaf growth and accumulation of phenolics? Oecologia 130:380-90. doi:10.1007/s00442-001-0826-z.

Rhoades, D. F. 1985. Offensive-defensive interactions between herbivores and plants: their relevance in herbivore population dynamics and ecological theory. American Naturalist 125:205-38.

Sene, M., T. Dore, and C. Gallet. 2001. Relationship between biomass and phenolic production in grain sorghum grown under different conditions. Agronomy Journal 93:49-54. doi:10.2134/agronj2001.93149x.

Speak, A., J. J. Rothwell, S. J. Lindley, and C. L. Smith. 2012. Urban particulate pollution reduction by four species of greenroof vegetation in a UK city. Atmospheric Environment 61:283-293.

Stagos, D., G. D. Amoutzias, A. Matakos, A. Spyrou, A. M. Tsatsakis, and D. Kouretas. 2012. Chemoprevention of liver cancer by plant polyphenols. Food and Chemical Toxicology 50:2155-70. doi:10.1016/j.fct.2012.04.002.

Starry, O., J. D. Lea-Cox, J. Kim, and M. W. Van Iersel. 2014. Photosynthesis and water use by two Sedum species in green roof substrate. Environmental and Experimental Botany 107:105-12. doi:10.1016/j.envexpbot.2014.05.014.

Tomás-Barberán, F. A., and J. C. Espín. 2001. Phenolic compounds and related enzymes as determinants of quality in fruits and vegetables. Journal of the Science of Food and Agriculture 81:853-76. doi:10.1002/jsfa.v81:9.

Trenberth, K. E., A. Dai, G. Van Der Schrier, P. D. Jones, J. Barichivich, K. R. Briffa, and J. Sheffield. 2014. Global warming and changes in drought. Nature Climate Change 4:7-22.

Unachukwu, U., S. Ahmed, A. Kavalier, J. Lyles, and E. Kennelly. 2010. Variation of phenolic and methylxanthine composition and anti-oxidant activity among white and green teas (Camellia sinensis var. sinensis (L.) Kuntze Theaceae). Journal of Food Science 75:C541C548. doi:10.1111/j.1750-3841.2010.01705.x.

Van Mechelen, C., T. Dutoit, and M. Hermy. 2014. Mediterranean open habitat vegetation offers great potential for extensive green roof design. Landscape and Urban Planning 121:81-91. doi:10.1016/j.landurbplan.2013.09.010.

Whittinghill, L. J., and D. B. Rowe. 2012. The role of green roof technology in urban agriculture. Renewable Agriculture and Food Systems 27:314-22. doi:10.1017/ S174217051100038X. 
Whittinghill, L. J., and O. Starry. 2016. Up on the roof: Considerations for food production on rooftops. In Sowing seeds in the city: Ecosystem and municipal services, eds. S. Brown, K. McIvor, E. Hodges Snyder, 325-38. Dordrecht, the Netherlands: Springer.

Wolf, D., and J. T. Lundholm. 2008. Water uptake in green roof microcosms: Effects of plant species and water availability. Ecological Engineering 33:179-86. doi:10.1016/j. ecoleng.2008.02.008.

Zietz, M., M. Schreiner, A. Weckmuller, A. Krumbein, S. Schmidt, L. W. Kroh, and S. Rohn. 2010. Genotypic and climatic influence on the antioxidant activity of flavonoids in kale (Brassica oleracea var. sabellica). Journal Agricultural Food Chemistry 58:2123-30. doi:10.1021/jf9033909. 